\title{
Colour in a Physical World: A Problem due to Visual Noise
}

JOHN MORRISON

Barnard College, Columbia University

jmorrison@barnard.edu

I develop a new problem for almost all realist theories of colour. The problem involves fluctuations in our colour experiences that are due to visual noise rather than changes in the objects we are looking at.

\section{Introduction}

There is a tension between our perceptual experiences and our physical theories. Our perceptual experiences tell us about a world full of yellow dandelions, blue sapphires, orange pumpkins, and white pebbles. Our best physical theories tell us about a world of spinning quarks, polarized leptons, and energized bosons. Because we have little trouble imagining how large things could be constructed out of small things, we seem to have little trouble imagining how dandelions, sapphires, pumpkins, and pebbles could be constructed out of quarks, leptons, and bosons, at least in rough outline. But we seem to have lots of trouble imagining how yellowness could be nothing more than the spin, polarity, energy, etc., of a dandelion's fundamental particles. As a result we are led to wonder whether there is room for colour in a physical world.

This paper is about conciliatory thinking, a widespread and influential way of thinking about colours and the way they fit into the physical world. There are two claims that are definitive of conciliatory thinking. The first claim is that the colours preserve the structure of our colour experiences. What is the 'structure' of our colour experiences? One of the central tasks of this paper will be to get clear about this notion. But, for now, an example might help. Just as we experience objects as located in space and thereby experience them as closer or further from each other, we also experience objects as coloured and thereby experience them as more or less similarly coloured. For example, an experience of a yellow dandelion, an orange pumpkin, and a 
blue sapphire also seems to be an experience of the dandelion and the pumpkin as more similarly coloured than the dandelion and the sapphire. And this seems to be built into the structure of our colour experiences. I will discuss other kinds of examples later.

The claim about structure can be motivated in several ways. One way is to appeal to the intuition that the structure of our experiences indicates essential truths about the colours because it reveals at least part of their essences. ${ }^{1}$ Another way is to appeal to the weaker intuition that the structure of our experiences indicates conceptual truths about the colours because it is built into our colours concepts. ${ }^{2}$ Yet another way is to argue that the structure of our experiences indicates contingent truths about the colours because it places a constraint on which properties we represent in the actual world and a property should only count as a colour if we actually represent it (or properties like it). ${ }^{3}$ For the purposes of this paper it will not matter which motivation a conciliatory thinker endorses.

There are a handful of philosophers of colour who reject the claim about structure. Some reject it because they think that the structure of our experiences merely provides a 'folk theory' of the colours, and as such they are comfortable with mismatch between the colours and the

\footnotetext{
${ }^{1}$ Many philosophers seem to share this intuition. Strawson (1989) claims that the whole nature of the colours is 'revealed' by experience. Harding (1991) says that the nature of the colours is 'laid bare' in experience. Campbell (1993) claims that it is part of 'common sense' that the essential facts about the colours are 'transparent' to us. Johnston (1992) claims that it is among our 'core beliefs' that we can know necessary truths about the colours by reflection on our experiences.

${ }^{2}$ A number of philosophers make claims in the vicinity. Wittgenstein (1921) says that it is 'unthinkable' that the colours could have different relations to one another. Broackes (1992) talks about 'phenomenal elements in our conception of the colours'. Yablo (1995) says that to know the colours one must know them in a 'subjectivity-involving way', which might indicate a commitment to the second claim, depending on how we understand this expression. While they do not go into the details, Boghossian and Velleman $(1989,1991)$ say that it is 'beyond question' that we can know necessary truths about the colours by introspection and Pautz (2006) says that it is 'obvious'.
}

${ }^{3}$ For reasons I will explore in a moment, it is sometimes difficult to determine whether someone accepts the claim about structure, and that is especially true for philosophers who say things that seem to correspond to this third motivation. None the less, let us canvass some likely candidates. McLaughlin and Jakab (2003) say that 'colour physicalism must be squared with the perceived similarity relations' and McLaughlin (2003) builds these relations into the functional specification of the colours. So does Cohen (2003a, 2003b). Bradley and Tye (2001) also seem to belong to this group. Thompson (1995) thinks that our theory of colour must accommodate our pre-theoretic intuitions, and he seems to think that these intuitions reflect the structure of our experiences. Byrne and Hilbert (2003) might belong in this group because they say it would be 'heroic' to deny that the colours bear similarity relations to one another. 
structure of our experiences. ${ }^{4}$ Others reject it because they think that the structure of our colour experiences indicates something about our physiology rather than about the colours themselves. ${ }^{5}$ But there are not many philosophers in this category.

The second claim that is definitive of conciliatory thinking is that the colours depend on physical properties such as spin, polarization, energy, and mass. There are many ways in which the colours might depend on these physical properties. For example, they might be identical to them, metaphysically necessitated by them, nomologically necessitated by them, have them as their dispositional grounds, or just co-vary with them in the actual world. I will understand the claim about dependence so that it is neutral between these possibilities. So understood, this claim is endorsed by almost all realists about colour, including all colour physicalists and most colour dispositionalists and colour primitivists.

Like the claim about structure, there are many ways to motivate the claim about dependence. For brevity, I am just going to focus on a motivation for the weakest kind of dependence. Intuitively, changing the physical properties of an object can change its colour. For example, bleaching a blue shirt can turn it white. Equally intuitively, these changes are systematic. For example, if you bleached an identical shirt you would expect it to likewise turn white. This motivates the claim that the colours at least co-vary with physical properties in the actual world.

To recap, the two definitive claims of conciliatory thinking are: the claim about structure (that the colours satisfy the structure of our colour experiences) and the claim about dependence (that the colours depend on physical properties). I think that it is helpful to see why these kinds of claims come in pairs. Suppose that in order for a property to count as yellowness it only needed to cause experiences of yellowness. In that case, it would be obvious that yellowness is a physical property because it is obvious that our experiences of yellowness have physical causes. In contrast, suppose that in order for a property to count as yellowness it needed to be an intrinsic and non-disjunctive property. In that case, it would be far less obvious whether yellowness

\footnotetext{
4 Matthen (1999) thinks about things in this way. Lewis (1997) and Jackson (1996) are tough cases. On the one hand, they frame the discussion around our folk theory of colour and admit that the folk theory of colour might need to be revised. But, on the other hand, they insist that some elements of our folk theory cannot be compromised, and among those elements seem to be characterizations of the structure of our experiences.
}

${ }^{5}$ Harman (1996) seems to think about things in this way. 
is a physical property because it is far less obvious whether dandelions and lemons, for example, share any intrinsic and non-disjunctive physical properties. As these examples demonstrate, the claim about dependence needs to be paired with a claim about what conditions a property must satisfy in order to count as a colour, and that is the role of the claim about structure. Thus we should not think of conciliatory thinking as the mere disjunction of two independent claims. Instead, we should think of it as an attempt to hold onto the claim about dependence despite the demands of the claim about structure.

In this paper I am going to develop a new problem for conciliatory thinking. I will argue that the most natural and plausible strategy for integrating the claim about structure and the claim about dependence is unsuccessful. I will thereby call into question the tenability of conciliatory thinking.

Of course, like all philosophical arguments, my arguments rely on auxiliary claims that someone could reject. However, as we will see, rejecting these claims would have some surprising, far-reaching, and counter-intuitive consequences. A conciliatory thinker should therefore find my arguments challenging even if she is not ultimately persuaded that her way of thinking is untenable.

Let us now address a complication. In large part because there is no standard vocabulary for talking about these matters, it can sometimes be difficult to determine whether a particular philosopher accepts the claim about structure. However, there is often plenty of indirect evidence. Sometimes that evidence comes from the fact that she endorses one of the motivations listed above. Other times it comes from the fact that she claims that colour solids (which are also called 'colour arrays' or 'colour spaces') not only capture the structure of our colour experiences but also capture the structure of the colours themselves. ${ }^{6}$ Here is a representative passage:

Colors are the kinds of properties that fit together in characteristic ways to form structured color arrays, with a distinctive 3-dimensional character. They are properties that as a group, form an internally related $4+2$ structure, built on the four unique, primary hues: green, red, blue, and yellow, and related to the black/white pair. (Maund 2006)

Finally, evidence that a philosopher accepts the claim about structure sometimes comes from the way in which she responds to the similarity objection, which is an influential argument that targets one strand of conciliatory thinking. The people who develop this objection claim

\footnotetext{
${ }^{6}$ See Bradley and Tye 2001, McLaughlin 2003, Byrne 2003, and Kalderon 2007.
} 
that we cannot identify the colours with physical properties because then there would be no genuine resemblance between yellow and orange, in which case, they conclude, the colours would not preserve the structure of our experiences. With few exceptions, philosophers of colour respond in two ways. First, they endorse the conclusion and infer that colours are not identical to physical properties. ${ }^{7}$ Second, they argue that there is indeed a genuine similarity between the relevant physical properties, thereby undermining the argument's crucial premiss. ${ }^{8}$ Either way, philosophers rarely respond by denying that there is a genuine resemblance between yellow and orange. Because there does not seem to be anything special about the similarities between colours, this suggests that most philosophers accept the more general claim that the colours satisfy the structure of our experiences.

I want to advertise two features of my arguments in advance. First, unlike existing arguments, my arguments target all strands of conciliatory thinking about colour. In the literature there are already arguments that target specific strands of conciliatory thinking. For example, as noted above, the similarity objection only targets the view that the colours are identical to physical properties, which is why it is often used to motivate other strands of conciliatory thinking, such as strands that merely insist that the colours supervene on physical properties. ${ }^{9}$ In contrast, my arguments target anyone who accepts the claim about dependence regardless of whether they think that the dependence is identity, metaphysical necessity, nomological necessity, or even contingent co-variation. Moreover, the fact that people typically use the similarity objection, which depends on the claim about structure, as the primary motivation for these other strands helps give my arguments added force- $-\mathrm{I}$ am using one of their own premisses against them.

Another example is a much-discussed argument targeting the strand of conciliatory thinking that categorizes colours as dispositions. Those who develop this objection allege that the colours are not

\footnotetext{
7 See Hardin 1988a, 2003; Johnston 1992; Maund 1995; McGinn 1983; Pautz 2003, 2006; and Thompson 1995.

${ }^{8}$ See Byrne 2003, Byrne and Hilbert 2003, Bradley and Tye 2001, Cohen 2003b, and McLaughlin 2003.

9 Why are these strands unthreatened by the similarity objection? An analogy might help: if minds are not identical to brains then your mind might resemble an alien's mind when you are both thinking about dandelions even if your brain does not resemble the alien's brain.
} 
dispositions because our experiences reveal what is essential to the colours and our experiences do not reveal that the colours are dispositions. ${ }^{10}$ The success of this argument hinges on the claim that our experiences reveal what is essential to the colours, and that goes far beyond what the claim about structure requires. As I have formulated it, the claim about structure is extremely weak. For example, it does not entail that our experiences reveal what is essential to the colours, that the colours must satisfy the structure of our colour experiences in virtue of their essences, or that the colours must satisfy the structure of our colour experiences in all metaphysically possible worlds. It just entails that the colours at least satisfy the structure of our experiences in the actual world. Therefore, unless there is a supplementary argument for this claim about what our experiences reveal, this other argument does not seem to extend to every strand of conciliatory thinking. Once again, what will set my arguments apart is their generality.

A second feature of my arguments that I want to advertise is that one cannot respond by merely adapting standard responses to other problems. For example, philosophers who want to undermine the similarity objection often appeal to a claim that we can roughly state as follows: an experience represents the disjunction of all the colours that reliably cause that experience. They use this claim to argue that redness and orangeness resemble one another even if they are identical to physical properties. ${ }^{11}$ Given the apparent usefulness of this claim in the context of the similarity objection, they might hope that it also gives them a way to undermine my arguments. But this claim is actually one of the premisses that I will use to call into question the tenability of conciliatory thinking and thus it obviously cannot help a conciliatory thinker avoid the problem. My arguments challenge conciliatory thinking in a novel way.

One last point. I will assume that white, black, and grey are colours because that will make it easier to print an important diagram. Nothing philosophically important will depend on this assumption.

\footnotetext{
${ }^{10}$ See, among others, Boghossian and Velleman 1991; Campbell 1993, 2002; Harding 1991; McGinn 1983; and Strawson 1989. See also Johnston 1992, though Johnston uses a slightly weaker premiss.

${ }^{11}$ See Bradley and Tye 2001 and Cohen 2003b. Their arguments draw on Opponent Processing Theory.
} 


\section{Preview}

It may be helpful to have an idea of where we are headed, so I will use a toy model to roughly sketch the main argument.

Suppose a collector of precious stones has a scale that displays one of four terms, 'tiny', 'small', 'large', or 'huge', depending on its measurement:

\begin{tabular}{ll}
\hline Display & Measurement $(x)$ \\
\hline tiny & $x \leq 10 \mathrm{mg}$ \\
small & $10 \mathrm{mg}<x \leq 11 \mathrm{mg}$ \\
large & $11 \mathrm{mg}<x \leq 12 \mathrm{mg}$ \\
huge & $12 \mathrm{mg}<x$ \\
\hline
\end{tabular}

Suppose also that the collector endorses three claims. The first claim is that 'tiny', 'small', 'large', and 'huge' represent properties that preserve the truth of certain conditionals, including:

(a) If a stone is not tiny, small, or large then it is huge

(b) If a stone is tiny and another stone is small then all stones with intermediate weights are tiny or small

The collector might regard (a) and (b) as part of the structure of the scale's system of representation.

The second claim is that each term represents a disjunction of weights. The collector might accept this claim because he wants 'tiny', 'small', etc. to refer to physical properties of the stones.

The third claim is an attempt to integrate the first two claims: it is an attempt to show that 'tiny', 'small', etc. represent disjunctions of weights that preserve the truth of conditionals like (a) and (b). In particular, it is the claim that 'tiny' represents the disjunction of all the weights that reliably cause the scale to output 'tiny', 'small' represents the disjunction of all the weights that reliably cause the scale to output 'small', etc.

The problem is that the first and third claims are inconsistent. Like all measuring instruments, the scale's measurements will be 'noisy'. For example, if a stone actually weighs eleven milligrams then the scale will none the less sometimes register more or less weight, and therefore will sometimes display 'tiny', 'small', 'large', and 'huge' (though not all at once). Noise often has the shape of a bell curve. For any stone that actually weighs eleven milligrams we 
might graph the probability that it will produce different measurements as follows:

Measurements of an $11 \mathrm{mg}$ stone

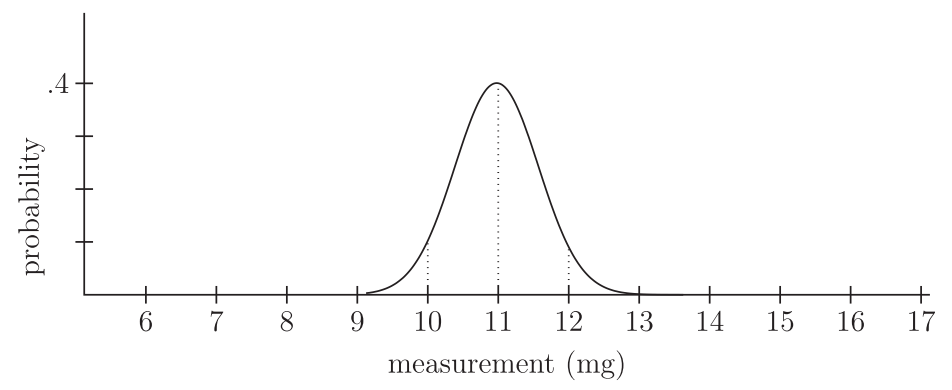

The area under the curve between ten and eleven is the probability that the scale will display 'small'. Likewise for 'tiny', 'large', and 'huge'. Because it is a symmetric probability distribution centered at eleven, and because it asymptotically approaches zero in both directions, all of these areas are less than one-half. Consequently, stones that weigh eleven milligrams have an equal likelihood of producing 'small' and 'large' as well as a non-zero likelihood of producing 'tiny' and 'huge'. As a result, they do not reliably produce 'tiny', they do not reliably produce 'small', etc.

This example reveals something very general about measuring devices: due to noise, as long as there is a continuum of stimuli and only countably many outputs, some range of stimuli will not reliably produce any particular output. In different devices the noise will have different causes. For example, in metallic scales it might be caused by random variations in the temperature of the coil, and in the human eye it might be caused by random variations in blood pressure.

We are now in a position to appreciate why the first and third claims are inconsistent. Due to the existence of noise, the third claim entails that 'tiny', 'small', 'large', and 'huge' represent disjunctions of weights that do not include eleven milligrams. Therefore, a stone that is eleven milligrams is not tiny, small, large, or huge, in which case (a) is false. Also, a stone that is nine milligrams will be tiny, a stone that is eleven and a half milligrams will be small, but a stone that is eleven milligrams will be neither tiny nor small, in which case (b) is false. Recall that the first claim is that 'tiny', 'small', 'large', and 'huge' represent properties that preserve the truth of (a) and (b). Therefore, the first claim and the third claim are inconsistent. 
In response, the collector must give up one of his claims. He might initially be tempted to give up the third claim. But recall that the third claim is part of the collector's attempt to integrate the first and second claims. Therefore, if he gives up the third claim then it is unclear whether his way of thinking is tenable.

I will argue that there is a similar problem for conciliatory thinking. In particular, I will argue that the most natural way to integrate the claim about structure and the claim about dependence is to appeal to a principle that I will label RELIABLE PRODUCTION, which is a principle about which colours our experiences represent. I will then argue that RELIABLE PRODUCTION is inconsistent with the claim about structure, at least if we accept some natural and plausible auxiliary assumptions. In particular, I will argue that the claim about structure implies that certain transitions in colour are 'full' in that there are no intermediate shades that are not represented. I will then argue that, due to visual noise, RELIABLE PRODUCTION implies that there are always intermediate shades that are not represented, in which case the two claims are inconsistent. That calls into question whether the claim about structure and the claim about dependence are compatible. I will then canvass possible responses and argue that, at best, those responses would commit conciliatory thinkers to surprising, far-reaching, and counter-intuitive claims.

Before I can state the full argument I need to identify the physical properties relevant to colour and say more about the two definitive claims of conciliatory thinking.

\section{Spectral dispositions}

There is no standard vocabulary for talking about the physical properties relevant to colour and, moreover, the existing vocabularies are often skewed to particular views. As a remedy, I will introduce a number of new terms, including 'spectral dispositions', which is my term for the physical properties that the colours depend on.

A good place to start is Newton's (1672) prism experiment. Newton cut a small hole in one of his laboratory's shutters, thereby allowing a narrow ray of sunlight to enter. He then used a prism to project a rainbow onto the opposite wall. Newton noted that different colours in the rainbow had different angles of refraction relative to the original ray of sunlight. He inferred that there is a connection between a light ray's angle of refraction and an observer's colour experiences. After 
Maxwell's (1881) subsequent discovery that a ray's angle of refraction varies with its wavelength, many philosophers and scientists concluded that there is a connection between the wavelengths of light rays and an observer's colour experiences. Even those who deny that actual objects are coloured ('colour eliminativists') can acknowledge this connection.

According to conciliatory thinking, the colours of objects depend on some of their physical properties. The properties in virtue of which objects reflect, absorb, and transmit light are among the properties that our best physical theories tell us about. Because they are also the properties in virtue of which objects cause colour experiences, conciliatory thinkers theorize that there is a connection between the colours of objects and the properties of objects in virtue of which they reflect, absorb, and transmit light. Let us explore this connection.

We need to start by introducing two technical terms. First, the spectral power distribution of a light ray is its intensity at each wavelength. We can graph the spectral power distribution of a light ray:

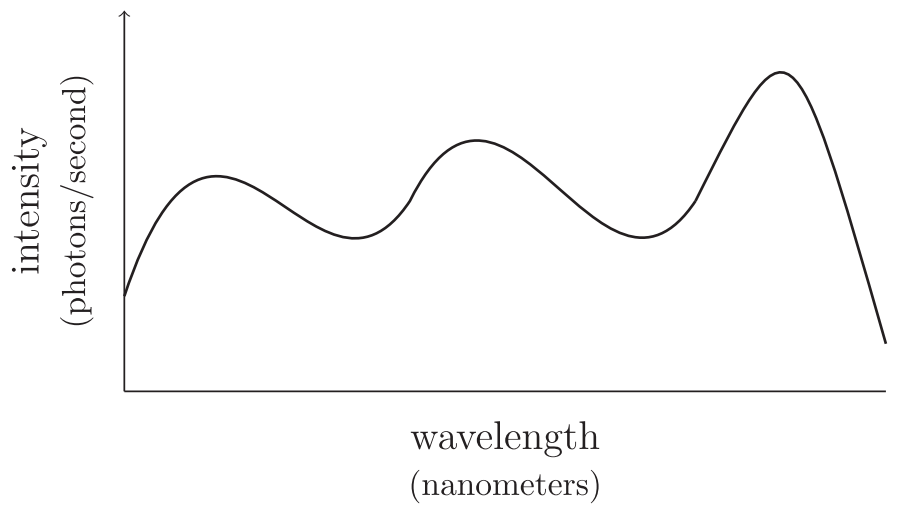

While objects do not themselves have spectral power distributions, they do reflect, emit, and transmit rays of light with different spectral power distributions. In different contexts the spectral power distribution of those light rays will be different. For instance, in conditions of low illumination most objects will reflect, transmit, or emit rays of light with low intensities at every wavelength. Leaving a more precise definition to a footnote, the spectral disposition of an object or volume is a function from each context to the spectral power distribution of the light rays reflected, transmitted, or emitted by that surface or 
volume in that context. ${ }^{12}$ Notably, even if two objects reflect, emit, and transmit rays of light with identical spectral power distributions in some contexts, they might have different spectral dispositions due to their behaviour in other contexts.

There is a widespread misconception about spectral dispositions that is due, in part, to a widespread misunderstanding of Newton's prism experiment. Many people take Newton's experiment to show that, for instance, whether we experience purple is exclusively a function of the intensity of light around 40onm, whether we experience green is exclusively a function of the intensity of light around 550 nm, whether we experience red is exclusively a function of the intensity of light around 650nm, and so on. As a result, they think that there is a straightforward way of lining up spectral dispositions and our colour experiences. However, that is not the case: there is no direct correlation between whether we experience purple, green, or red and the intensity of light reflected at just those wavelengths.

For instance, suppose two objects reflect light rays with the following spectral power distributions:

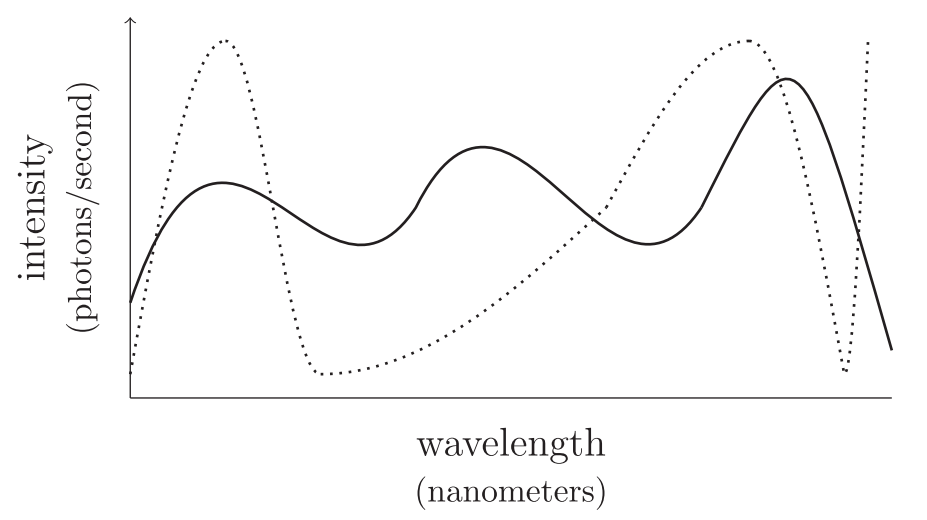

\footnotetext{
${ }^{12}$ Light is electromagnetic radiation between $400 \mathrm{~nm}$ and $700 \mathrm{~nm}$. Spectral power distributions are functions from all real numbers between 400 and 700 (wavelengths of light) to real numbers between o and $\infty$ (intensity). The total illuminant is a specification of the angle of incidence, spectral power distribution, and polarity of the light that reaches the object. The spectral disposition of a surface or volume is the function from each total illuminant to the spectral power distribution and polarity of the light rays reflected, transmitted, or emitted by that surface or volume to each location.

Traditionally, conciliatory thinkers have focused exclusively on reflected light, setting aside transmitted and emitted light and ignoring the complications due to polarity and angle of incidence, at least in their official formulations. But I cannot identify a good reason for this tradition.
} 
Despite the different spectral power distributions of the reflected light rays we might have indistinguishable colour experiences. ${ }^{13}$ Accordingly, the relationship between spectral dispositions and colour experiences is more complicated than Newton's experiment has led many to believe.

This has an important consequence: when associating colour experiences with collections of spectral dispositions we cannot rely on natural, human-independent divisions of spectral dispositions. Instead, just as in the toy model the collector relied on causal relations between the scale's outputs (e.g. 'tiny') and weights, we apparently need to rely on causal relations between our visual experiences and spectral dispositions. More on this later.

\section{First claim: dependence}

There are two claims that are definitive of conciliatory thinking: a claim about dependence and a claim about structure. The claim about dependence is that the colours we represent depend on collections of spectral dispositions. But which collections? And what kind of dependence? In order to precisely and concretely state the problem for conciliatory thinking it will be helpful to focus on particular answers to these questions.

Before we start, it is necessary to introduce a new term. We might think of the colours as forming a tree that is analogous to the zoological tree. Near the top of the tree are properties like yellow, green, and grey. Further down are properties like amber, mustard, lime, jade, ash, and charcoal. And at the bottom are the foundational colours, which are the most specific colours. By definition, objects with the same foundational colour must instantiate all the same colours; if one is charcoal then the other is charcoal, if one is grey then the other is grey, and so on.

The best way to develop the claim about dependence is to break it down into four steps. The first step is to decide how fine-grained to make the foundational colours (which is analogous to deciding how fine-grained to make species classifications in the zoological tree). There is a range of possibilities. Towards one extreme is the possibility that the foundational colours are as fine-grained as the spectral

\footnotetext{
${ }^{13}$ This is due to the way in which the cones in our eyes respond to light. See Hurvich 1981.
} 
dispositions. Towards the other extreme is the possibility that they are as coarse-grained as the discriminations of the human visual system. To keep things simple, I will suppose that the foundational colours are as fine-grained as the spectral dispositions. While most conciliatory thinkers will accept this assumption, some will deny it. As a way of streamlining the discussion I will treat their response as an objection and consider it later.

The second step is to decide which spectral dispositions correspond to foundational colours (which is analogous to deciding which organisms correspond to species in the zoological tree-e.g. viruses? bacteria?). I will suppose that every spectral disposition corresponds to a foundational colour. While some might reject this supposition, I will subsequently argue that this would have surprising and counterintuitive consequences.

The third step is to decide how higher-up colours like red relate to lower-down colours like scarlet (which is analogous to deciding how a genus relates to its species in the zoological tree). To make my discussion more concrete I will suppose that the non-foundational colours are disjunctions of the foundational colours. ${ }^{14}$ For example, where ' grey $_{167}$ ' etc. are names for foundational colours, charcoal might be the disjunction grey $_{167} \vee$ grey $_{168} \vee \ldots \vee$ grey $_{199}$. Nothing will depend on this supposition.

The final step is to decide how the colours depend on the spectral dispositions. One possibility is that the colours are identical to spectral dispositions (or their shared bases). ${ }^{15}$ Another possibility is that the colours supervene in some way on the spectral dispositions so that they co-vary without being identical. ${ }^{16}$ A third possibility is that the colours

\footnotetext{
14 Alternatively, the non-foundational colours might be determinables (see Yablo 1995) or sets (see Hilbert 1987).

15 See, for example, Averill 1985; Byrne and Hilbert 1997a, 2003; Dretske 1994; Hilbert 1987; Lycan 1996; Smart 1975; and Tye 1995, 2002. Note that Smart thinks that it is contingent identity. For instances of the view that the colours are identical to the shared bases of certain spectral dispositions see Armstrong 1968, 1987; Jackson and Pargetter 1987; Jackson 1996; and McLaughlin 2003.

16 See, for example, Broackes 1992, Campbell 1993, and Yablo 1995. Yablo thinks that it is local and metaphysical supervenience and Campbell thinks that it might just be global and nomological supervenience (assuming he would include natural laws among the 'physical characteristics' of a world).
} 
are 'response-dependent' in that they are constituted by relations between objects and observers that hold in virtue of the spectral disposition of the object as well as the make-up of the observer. ${ }^{17,18}$ I will focus on the weakest kind of dependence because that will demonstrate that it is possible to generate the problem for any strength of dependence. Let us say that a foundational colour minimally depends on a spectral disposition just in case in the actual world something instantiates that spectral disposition if and only if it instantiates that colour. Similarly, let us say that a non-foundational colour minimally depends on a disjunction of spectral dispositions just in case in the actual world something instantiates one of those spectral dispositions if and only if it instantiates that colour.

With this background we can state the claim about dependence as we have developed it:

DEPENDENCE

The colours that we represent minimally depend on disjunctions of spectral dispositions

In the next section I will introduce the claim about structure. I will then argue against the most straightforward proposal for integrating these claims. I will subsequently argue that other ways of developing conciliatory thinking confront the same problem.

\section{Second claim: structure}

The second claim is easy to state but difficult to understand:

STRUCTURE

The colours that we represent preserve the structure of our colour experiences

In this section I will develop an understanding of STRUCTURE that brings out what I think is essential to conciliatory thinking. In subsequent

\footnotetext{
${ }_{17}$ See, for example, Cohen 2004, Evans 1984, Johnston 1992, Kripke 1980, McGinn 1983, and Peacocke 1984 .

${ }^{18}$ At least when endorsed by a conciliatory thinker, these claims do not perfectly line up with so-called 'physicalism', 'realist primitivism', and 'dispositionalism'. Broad 1914 and Cornman 1975, for example, should probably be classified as examples of 'realist primitivism' but Broad and Cornman would deny that the colours depend on any physical property. Also, McDowell 1985 should be classified as 'dispositionalist' but McDowell never commits himself to the view that the colours depend on spectral dispositions. For the traditional classifications of colour theories see Pautz 2009 and Byrne and Hilbert 1997b.
} 
sections I will use it to develop a problem for conciliatory thinking. In response, a conciliatory thinker might suggest that we should understand it in some other way. However, for reasons I will introduce later, I doubt that this will allow her to avoid the problem.

In order to understand what I mean by 'represent', 'preserve', and 'structure', it is necessary first to understand what I mean when I say that an experience 'tells us' something. I am using 'tells us' to pick out a phenomenon that we can grasp pre-theoretically but that admits of many different theoretical glosses. It roughly lines up with what people are talking about when they talk about 'how things look', 'how things visually appear', and what is 'experientially presented'. For present purposes, I will just highlight two of its characteristics. First, what our perceptual experiences tell us can be inconsistent with our background beliefs. For instance, even if we believe that the lines in the Müller-Lyer illusion are the same length, an experience of that illusion will still tell us that the lines are different lengths. Second, what our experience tells us must be accessible by conscious introspection. For instance, the mere fact that a sub-personal module in our visual system contains information about a thing is not enough for our visual experiences to tell us about that thing.

I am using 'represent' to pick out a related phenomenon. If an experience tells us that something is yellow then that experience has an intentional relationship to yellowness. ${ }^{19} \mathrm{I}$ am picking out that relationship by saying that the experience represents yellowness. ${ }^{20}$

19 The nature of this relationship depends on one's view about the content of what our experiences tell us. For example, if it is a Russellian proposition then redness is a constituent of what our experience tells us. Alternatively, if it is a Fregean proposition then redness is picked out by a constituent of what our experience tells us.

${ }^{20}$ There are many ways to talk about visual experiences. Those who are more familiar with other ways of talking might benefit from an explicit comparison. First, some people use 'represent' in a more restrictive sense. For example, there is a debate about whether experiences represent properties, acquaint us with properties, or are merely 'raw feels' that dispose us to form beliefs about properties. Participants in this debate must be using 'represent' in a more restrictive way than I am because, as long as everyone agrees that our visual experiences support beliefs in a consciously accessible way, everyone should agree that experiences represent properties in my sense of 'represent'.

Second, there is an active debate about an experience's 'representational content', and on some accounts an experience's representational content might not be the same as what it tells us. For example, perhaps due to epistemological considerations, representational contents are impoverished in that they do not include information about colour similarities. None the less, it should be uncontroversial that our experiences tell us about colour similarities. Thus, it should be uncontroversial that our colour experiences represent colour similarities in my sense of 'represents'. 
Note that while I am using 'tells us' and 'represents' to pick out different relations, it will not be crucial that you keep track of that difference.

Let us now use examples to clarify what it means to say something belongs to the 'structure' of our experiences. In a given context, consider an experience of both a pumpkin and a dandelion. That experience might tell us that the pumpkin is a certain shade of orange and that the dandelion is a certain shade of yellow, in which case our experience will thereby tell us that there is a difference between the colour of the pumpkin and the colour of the dandelion. We might think of the relationship between the first thing (that the pumpkin is a certain shade of orange and that the dandelion is a certain shade of yellow) and what our experience thereby tells us (that there is a difference between the colour of the pumpkin and the colour of the dandelion) as due to the structure of our experience. We might characterize the structure of our experiences as follows: if one thing is that shade of red and another thing is that shade of yellow then they are different colours. Therefore, those shades preserve the structure of our experience only if they preserve the truth of this conditional.

For our next example, consider an experience of a dandelion, pumpkin, and sapphire. If that experience tells us that the dandelion is a certain shade of yellow, the pumpkin is a certain shade of orange, and the sapphire is a certain shade of blue then it thereby tells us that the colour of the dandelion resembles the colour of the pumpkin more than the colour of the sapphire. Therefore, we might characterize the structure of our experiences: if one thing is that shade of yellow and another thing is that shade of orange then they have colours that resemble each other more than that shade of blue. Therefore, those shades preserve the structure of our experience only if they preserve the truth of this conditional.

It would be ideal if we had a complete theory about the structure of our experiences. But we do not, and it is beyond the scope of this paper to develop one. How, then, are we supposed to determine what is and what is not included in this structure? There is no algorithm. We must often rely on introspection to deliver a verdict about particular cases. Consequently, as much as possible, we should focus our attention on clear cases. And that is exactly what I will try to do in the next section.

It might be helpful to compare STRUCTURE to analogous claims about other properties, like odours and shapes. Our odour experiences seem less structured than our colour experiences: there seem to be fewer 
conditionals linking a musky odour to other odours than linking crimson to other shades. The analogous claim about odours therefore seems to place less pressure on what it is for a property to be a odour. In contrast, our shape experiences seem more structured than our colour experiences. For example, the shapes we represent seem to vary in only three dimensions, excluding variation in any of the additional dimensions described by physics. A conciliatory thinker about shape might therefore have a very hard time showing that the shapes we see are actually instantiated.

While conciliatory thinkers about colour do not need to take a stand on any analogous claims about other properties, I suspect that few would accept the analogous claim about shapes. While the reasons are hard to articulate, at bottom there just does not seem to be as tight a connection between shapes and experiences as there is between colours and experiences. As a result, while the motivations listed in the opening section lead many to accept STRUCTURE, parallel motivations lead few if any to accept the analogue about shapes (or weights, sizes, speeds, etc.). Arguably, that is where conciliatory thinking goes wrong. I will return to this issue later.

\section{Third claim: reliable production}

The two definitive claims of conciliatory thinking are:

STRUCTURE

The colours that we represent preserve the structure of our colour experiences

DEPENDENCE

The colours that we represent minimally depend on disjunctions of spectral dispositions

In this section I will describe the most natural strategy for integrating STRUCTURE and DEPENDENCE into a coherent whole. This strategy centres on a principle that I will title RELIABLE PRODUCTION. In the next section I will argue that RELIABLE PRODUCTION is inconsistent with STRUCTURE, at least if we accept some natural and plausible auxiliary assumptions. By undermining the most natural strategy for integrating STRUCTURE and DEPENDENCE I will cast doubt on their compatibility.

Let us start by introducing the strategy. STRUCTURE and DEPENDENCE are both about the colours we represent. Together, they imply that the colours we represent both preserve the structure of our colour 
experiences and minimally depend on disjunctions of spectral dispositions. We therefore need a principle that specifies which colours we represent. This principle should allow us to deduce the structural relationships between those colours (in order to vindicate STRUCTURE), and which spectral dispositions underlie those colours (in order to vindicate DEPENDENCE). The most natural principle can be roughly stated: an experience represents the disjunction of all the foundational colours that reliably produce that experience. More precisely:

\section{RELIABLE PRODUCTION}

An experience represents a disjunction of some foundational colours if and only if in a certain type of person in a certain type of context (i) exposure to each of the relevant foundational colours reliably produces that experience, and (ii) no additional foundational colours reliably produce that experience.

RELIABLE PRODUCTION specifies which non-foundational colours we represent. As we will see, it allows us to deduce structural relationships between those non-foundational colours, thereby potentially vindicating STRUCTURE. It also allows us to deduce which spectral dispositions underlie those non-foundational colours. Because foundational colours are as fine-grained as spectral dispositions, if we know which foundational colours make up a non-foundational colour then we know which spectral dispositions underlie that non-foundational colour. RELIABLE PRODUCTION thereby potentially vindicates DEPENDENCE.

RELIABLE PRODUCTION is attractive for many reasons. First, it implies that we represent colours that preserve important aspects of the structure of our colour experience. For example, no foundational colour can reliably produce both an experience of a shade of orange and an experience of a shade of yellow. A foundational colour can at most reliably produce one of these experiences. Therefore, RELIABLE PRODUCTION implies that an experience of a pumpkin and an experience of a dandelion represent non-overlapping disjunctions of foundational colours. As a result, RELIABLE PRODUCTION implies that an experience of a pumpkin and an experience of a dandelion represent different colours. In this way, RELIABLE PRODUCTION helps a conciliatory thinker show that the colours we represent preserve at least one aspect of the structure of our experiences: if one thing is that shade of orange and another thing is that shade of yellow then they are different colours.

Why is it important that RELIABLE PRODUCTION implies that an experience of a pumpkin and an experience of a dandelion represent 
non-overlapping colours? An analogy might help. Suppose that two friends independently tell you which countries they might visit over the holiday. They thereby told you that they will be visiting different countries only if their lists did not overlap.

Second, RELIABLE PRODUCTION nicely explains why the same experience can accurately represent objects that reflect light differently but that appear the same to us ('metamers'). Recall from section 3 that objects that reflect light differently can reliably cause exactly the same colour experience. RELIABLE PRODUCTION implies all those objects are accurately represented by that experience.

Third, it coheres with popular theories about how our experiences represent the colours. According to these theories, our experiences represent colours in virtue of this very kind of causal co-variation. ${ }^{21}$ These theories dovetail nicely with conciliatory thinking about colour because we might think of them as exemplifying conciliatory thinking about representation in so far as they try to show how representational properties depend on physical properties. They are also especially attractive in the case of colour because facts about our evolutionary history and social practices seem too coarse-grained to explain why an experience represents a certain disjunction of foundational colours rather than a slightly smaller or larger disjunction. It is worth noting that RELIABLE PRODUCTION is consistent with many different permutations of these theories. For instance, when selecting the relevant type of person and the relevant type of context one might focus on ordinary people in ordinary contexts. Or one might focus on idealizations of ordinary people in idealizations of ordinary contexts. Or, in a nod to teleologial theories, one might focus on our distant ancestors in the context in which they evolved.

None the less, even those who are sceptical of causal theories of representation in the case of colour might still endorse RELIABLE PRODUCTION. That is because RELIABLE PRODUCTION is not a claim about how, or in virtue of what, our experiences represent colours. It is just a claim about which colours our experiences represent.

Fourth, RELIABLE PRODUCTION is at the heart of many attempts to undermine the similarity objection. In particular, if RELIABLE PRODUCTION is conjoined with an influential theory about how our visual system produces colour experiences then, as Bradley and Tye

\footnotetext{
${ }^{21}$ See, for example, Dretske 1981 and Tye 1995.
} 
(2001) and Cohen (2003b) have argued, there apparently is a similarity between the spectral dispositions that produce similar colour experiences, which potentially establishes that there is a similarity between the colours that depend on those spectral dispositions. The details of these attempts are complicated and, fortunately, unnecessary for our purposes.

In sum, there are many reasons why conciliatory thinkers should be attracted to RELIABLE PRODUCTION and correspondingly there are many reasons why they should be hesitant to give it up.

One final point. While RELIABLE PRODUCTION leaves it open where we should draw the line between reliable and unreliable production, it assumes that the line is above fifty percent. In section 8 I will consider what happens if we lower the threshold below fifty percent.

\section{The problem}

The problem is that RELIABLE PRODUCTION is incompatible with STRUCTURE. Here is a rough sketch of why. I am about to introduce a claim that the conciliatory thinker should accept. I will label it NOISE. Together, RELIABLE PRODUCTION and NOISE imply that there are colours that our experiences never represent. For example, they imply that there is a colour that falls between charcoal and ash such that our experiences never represent it on its own or as part of a disjunction of colours. But I will argue that it is part of the structure of our colour experiences that some colours together 'fill' a path through colour space in that there are no intermediate colours missing. I will conclude that conciliatory thinkers should give up RELIABLE PRODUCTION.

As its name suggests, NOISE is a consequence of the fact that our visual system is noisy. In our toy example involving the scale, it was easy to imagine how noise would manifest itself-the scale would sometimes display different terms even though it is weighing the same stone. It is therefore natural to wonder: How does noise in the visual system manifest itself? Close your eyes and closely attend to your experience. At least if you are like me, you will notice small, constant changes in your experience's phenomenal character; your experience will seem to 'shift' between experiences with slightly different phenomenal characters. This 'shifting' does not go away just because you open your eyes. It just becomes easier to ignore, which is why it often takes practice to notice it. The existence of visual noise 
is well established and much discussed in the scientific literature. To quote a vision scientist nearly at random, Dennis Pelli (1990, p. 12) observes that, 'noise arises in virtually all neural elements of the visual system from photoreceptor to cortex.' Among its many biological causes are rapid variations in blood pressure, fluctuations in the temperature of the retina, and interference along neural pathways. Noise is an ineliminable feature of any physical process and therefore, as long as our conscious experiences at least supervene on physical processes, our experiences must be noisy.

The existence of visual noise has an important consequence. ${ }^{22}$ Suppose that an object with a certain foundational colour $\left(\right.$ grey $\left._{256}\right)$ reliably produces a certain experience (E1). If we gradually change the foundational colour of that object then at some point it will start producing that experience less often. It will correspondingly start to produce another experience (E2) more often, until we reach a foundational colour $\left(\right.$ grey $\left._{343}\right)$ that reliably produces that other experience. Moreover, because noise is asymptotic, there is always some probability that each of these foundational colours will produce other experiences ( $E_{3}, E_{4}$, etc.).

I think that it helps to represent the situation with a graph. Where E1 is represented by a dashed line, E2 is represented by a dotted line, and $\mathrm{E}_{3}$ is represented by a more densely dotted line, we might depict the situation as follows:

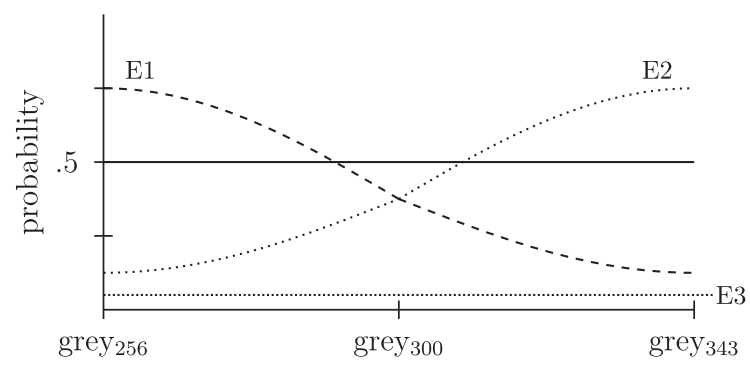

foundational colours

${ }^{22}$ Visual noise has other important consequences. See, for example, Hardin $1988 \mathrm{~b}$ and Hellie 2005 for a discussion of its consequences for our understanding of the phenomenal sorites. 
The probability that a grey ${ }_{300}$ object will produce an E1 experience is the same as the probability that it will produce an E2 experience, and there is a non-zero probability it will produce an $\mathrm{E}_{3}$ experience. As a result, it does not produce any particular experience more than fifty percent of the time. ${ }^{23}$ Hence:

\section{NOISE}

For any observer and any context, if two foundational colours reliably produce different experiences, then there is a foundational colour between them that does not reliably produce any particular experience (even if it will always produce some experience or another).

Some conciliatory thinkers might hope to undermine NOISE by getting rid of all the biological causes of noise in the relevant observer's visual system. One strategy is to choose a perfectly ideal observer whose visual system is noise-free. Another strategy is to specify the context so precisely that all the biological factors that contribute to visual noise, including the observer's blood pressure, are all specified. ${ }^{24}$ However, these strategies fail because quantum indeterminacies by themselves produce enough noise to guarantee the truth of NOISE, at least if we assume that the relevant observer's visual experience cannot take infinitely long measurements. ${ }^{25}$

Of course, a conciliatory thinker could just deny that the relevant context is governed by the laws of quantum mechanics, or even that the observer cannot take infinitely long measurements, but I think it is clear that this medicine is worse than the disease. It might help to note that, to the best of my knowledge, no existing theories of visual

${ }^{23}$ Things get more complicated if there are uncountably many visual experiences. But, in that case, the probability that a foundational colour causes any particular visual experience is zero. Therefore, anyone attracted to reliable production would need to divide visual experiences into countably many groups. Setting aside whether there is any privileged way to group them, we could just think of ' $E 1$ ' and ' $\mathrm{E2}$ ' as names for groups of experiences, in which case the argument proceeds as before. Also, I doubt that there are uncountably many colour experiences because I doubt that the brain could generate so many different experiences.

${ }^{24}$ McLaughlin 2003 adopts a strategy like this to solve a different problem: the problem of variation.

${ }^{25}$ This is a result that I have proven in a technical report with David Anderson. See Morrison and Anderson 2011. The proof utilizes two facts. First, due to quantum indeterminacies, measurements of intensity will be at least as noisy as the Poisson distribution. See Fox 2006, pp. 76-80. Second, due to the quantum indeterminacies responsible for Doppler shifts, measurements of wavelength will be at least as noisy as the Cauchy-Lorentz distribution. See Dicke 1953. 
representation depend on such exotic contexts or observers. It might also help to note that if the conciliatory thinker starts tinkering with the laws of nature in the relevant context then there is no guarantee that objects in that context will have the same kinds of spectral dispositions as actual objects, in which case our colour experiences will not represent colours that are actually instantiated, and that is one of the primary motivations for conciliatory thinking.

At this point, one might wonder: Why are we taking it for granted that grey $_{300}$, and the properties like it, are colours? Recall that we are assuming that the foundational colours are as fine-grained as the spectral dispositions, and that all spectral dispositions correspond to foundational colours, in which case grey $_{300}$ is a colour because it corresponds to a spectral disposition. In the next section I will consider what happens if we dispense with these assumptions.

Let us now identify a consequence of RELIABLE PRODUCTION and NOISE. NOISE implies that there are foundational colours, like grey $_{300}$, that do not reliably cause any particular experience. RELIABLE PRODUCTION then implies that there is no experience that represents a disjunction that includes any of these foundational colours. Where 'charcoal' picks out the colour represented by E1 and 'ash' picks out the colour represented by E2, we might depict the situation as follows:

$$
\overbrace{\ldots \vee \text { grey }_{256} \vee \ldots \vee \text { grey }_{285}}^{\text {charcoal }} \ldots \text { grey }_{300} \ldots \underbrace{\text { grey }_{315} \vee \ldots \vee \text { grey }_{343} \vee \ldots}_{\text {ash }}
$$

More generally, RELIABLE PRODUCTION and NOISE logically entail:

\section{MISSING}

For any two colour shades that we represent, there is a foundational colour between them such that our experiences never represent a disjunction that includes it.

I will now argue that MISSING is incompatible with STRUCTURE. That will establish that the conciliatory thinker should reject RELIABLE PRODUCTION.

MISSING will embarrass many conciliatory thinkers because it has the incredible consequence that there is a colour between charcoal and ash that is 'invisible' in the sense that we could never even represent a disjunction that includes that colour. For example, a grey $_{3 \text { oo }}$ wall would always be misperceived as charcoal or ash. MISSING might even be incompatible with commitments shared by many conciliatory 
thinkers. For instance, it might be incompatible with the view that we can know everything about the nature of the colours by mere reflection on our visual experiences. ${ }^{26}$ It might also be incompatible with the view that $\phi$ is a colour only if things sometimes look $\phi$ to us. ${ }^{27}$ None the less, I will identify a problem with MIssing that does not depend on whether one endorses these views: I will argue that it implies that the colours we represent do not preserve the structure of our experiences.

As noted previously, we can think of the colours as filling a colour solid, which is a three-dimensional solid where the axes correspond to hue, brightness, and saturation. I will talk about lines through that solid as paths through colour space. ${ }^{28}$ Holding this paper at arm's length, consider your experience of the following strip:

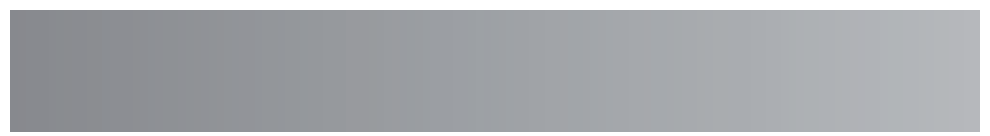

Your experience represents a series of colours, including (let us say) ash and charcoal. I claim that your experience tells you that these colours together 'fill' a path through colour space so that there are no missing colours. This is not to say that your experience individually represents each intermediate foundational colour. Given the number and grain of the foundational colours, that would be implausible.

26 See, for example, Campbell 1993, Strawson 1989, Harding 1991.

27 See Peacocke 1984 and McGinn 1983.

${ }^{28} \mathrm{I}$ am ignoring a complication. If foundational colours are as fine-grained as spectral dispositions then they will fill an infinite-dimensional space. As a result, there will be many different projections from that space to three-dimensional spaces, leaving it unclear which of them are projections to colour solids. Part of the problem is that there is controversy about how to give 'hue', 'brightness', and 'saturation' a precise physical meaning (see Land 1977, Hulbert 1986), and therefore, because we are assuming that every spectral disposition corresponds to a foundational colour, it is unclear which changes in foundational colour correspond to changes in hue, brightness, and saturation. Fortunately, my argument only requires that the relevant projection have the following property: letting $x, y$, and $z$ be locations in the infinite dimensional space, letting $x^{\prime}, y^{\prime}$, and $z^{\prime}$ be their projections in the colour solid, and letting $<$ be an ordering: if $x<y<z$ then $x^{\prime}<y^{\prime}<z^{\prime}$. Note that if there were no such projection then the colours would fail to preserve the similarity orderings that are a part of the structure of our colour experiences, and therefore conciliatory thinking would fall apart for a different reason.

29 Note that 'fill' is not synonymous with 'density'. An analogy might help. One might represent the intervals $[0,1]$ and $[1,2]$ as together filling $[0,2]$ without representing any of these intervals as dense because one might not represent any relations between the points in the intervals. Additionally, while 'fill' picks out a relation between intervals, 'dense' picks out a monadic property of an interval. For similar reasons, 'fill' is not synonymous with 'continuous'. 
More plausibly, there just seem to be no gaps between ash, charcoal, and the other non-foundational, disjunctive colours that you represent. $^{29}$ This claim is supported by introspection. It might help to try to picture an intermediate colour that is absent from the above strip. If you are like me, it is impossible.

There is a useful parallel with another kind of experience. Consider your experience as you look at a glass full of water. That experience would tell you that if water occupies two points then it also occupies all the intermediate points. This is not to say that your experience individually represents each point as occupied. Given the number and grain of those points, that would be implausible. More plausibly, there just seem to be no gaps between the smallest regions you represent. This claim is supported by introspection. It might help to try to imagine that the water fills more of the glass. If you are like me, it is impossible.

I also claim that, in virtue of what your experience of the strip tells you about ash, charcoal, etc., your experience thereby tells you that these colours together fill a path through colour space. Consider that it does not seem possible for your experience to represent the same colours in the same order but fail to tell you that these colours together fill a path through colour space. Consider also that you do not need to first check each colour to make sure it is included: your experience immediately tells you that the colours together fill a region of colour space-it seems to be built into your representation of ash, charcoal, etc. ${ }^{30}$

There is another helpful parallel with the water experience. In virtue of what your experience tells you about the water inside smaller regions in the glass, your experience would thereby tell you that water fills the glass. Consider that it does not seem possible for your experience to tell you that water continues to fill the same smaller regions

For example, unlike 'fill', 'continuity' picks out a property of a function from one interval to another.

${ }^{30}$ What exactly does your experience tell you about the strip's colouring? There is room for two views. On the one hand, your experience might represent parts of the strip in a way that does not distinguish the colours within them. From the perspective of your experience, each part might be completely homogenous with respect to colour. For example, your experience might represent one part as homogeneously ash and another part as homogeneously charcoal. But, on the other hand, it is also consistent with the possibility that your experience represents each part as continuously transitioning in colour, so that, e.g., one part is represented as continuously transitioning from ash to charcoal. See Fara 2001, pp. 18-25 for a discussion of the tension between supposing that our experience represents homogenous regions and supposing that our experience represents continuous transitions. 
in the glass but the water no longer fills the entire glass. Consider also that you do not need to first check each point in the glass: your experience immediately tells you that the water fills the glass-it seems to be built into your representations of the smaller regions.

Note I am describing a sufficient condition for having an experience of colours as filling a path through colour space: if you represent ash, charcoal, etc. in that order then you will have an experience of colours as filling a path through colour space. I am not describing a necessary condition. For all I have said, it might be possible to have that kind of experience without representing any particular colours like ash or charcoal.

Putting this all together, it is part of the structure of your experience that: if ash, charcoal, etc. are ordered in a certain way then these colours together fill a path through colour space. Ash and charcoal satisfy that conditional only if they are adjacent or overlapping regions of colour space. Therefore, STRUCTURE implies that ash and charcoal really are adjacent or overlapping regions of colour space.

The problem is that MISSING is incompatible with this implication. MISSING implies that ash and charcoal are not overlapping or adjacent regions because MISSING implies that there is a colour like grey ${ }_{300}$ that is neither ash nor charcoal. Therefore, MISSING is incompatible with STRUCTURE.

Let us review. The most natural way to integrate DEPENDENCE and STRUCTURE is to appeal to RELIABLE PRODUCTION. However, there is a problem: given some plausible auxiliary claims, STRUCTURE and RELIABLE PRODUCTION are incompatible. Conciliatory thinkers must therefore find another strategy or deny one of the auxiliary assumptions.

One of the features of my argument that is worth pointing out is that, because it focuses on an arbitrary context and an arbitrary observer, its conclusion extends to all contexts and all observers, at least if we restrict ourselves to what is nomologically possible. More precisely, for any given context and any given observer, there will be some 'missing' colours. Consequently, my arguments generate a problem for those who think that colours are relative to observers and contexts ('colour relativists') as well as those who just think that colour representation is highly context-sensitive.

It is also worth re-emphasizing one of the features of my argument that I advertised at the beginning. My argument focuses on the weakest kind of dependence: minimal dependence. It therefore establishes a problem for conciliatory thinking regardless of how the colours depend on the spectral dispositions. Among other possibilities, the 
colours might be identical to them, metaphysically necessitated by them, nomologically necessitated by them, or have them as their dispositional grounds.

In the next section I will consider nine responses and in the penultimate section I will consider another strategy.

\section{Responses}

Let us begin by clarifying the dialectical situation. My argument is a problem for conciliatory thinking, not a refutation. One can respond by giving up conciliatory thinking, giving up RELIABLE PRODUCTION, or giving up one of the auxiliary assumptions. Our goal is to determine which option is best. Therefore, the mere fact that it is possible to reject one of the auxiliary assumptions has little significance-after all, in philosophy it is possible to deny any assumption. The conciliatory thinker must show that she can reject one of the assumptions without committing herself to something equally problematic. I will argue that she cannot.

The first response targets my analysis of the experience of the colour strip. I claim that your experience tells you: ash, charcoal, etc. together fill a path through colour space. It is tempting to respond that your experience only tells you something weaker: that ash, charcoal, etc. together fill a path through the space of all the colours that you can represent. I think that this response is unattractive for two reasons. First, except perhaps in atypical circumstances, it is implausible to suppose your colour experiences tell you about other colour experiences, and, building on this, it is implausible to suppose that your colour experiences tell you what can be represented by other colour experiences, yet that is exactly what would be happening if your experience told you about the space of all the colours that you can represent. Second, it seems unmotivated. One might think it is motivated by the thought that if something is in principle not individually representable then it should be excluded from the domain of all our representations. But the missing fundamental colour is in principle representable; just suppose that the relevant observer's experiences were calibrated so that grey $_{256}$ is the missing colour instead of grey $_{300}$. In that case we would represent a non-foundational colour that has grey $_{3 \text { oo }}$ among its disjuncts. Further, our visual experiences presumably cannot represent individual spatial points or individual foundational colours, yet we presumably can still represent collections 
of spatial points and collections of foundational colours. Thus, the fact that we cannot individually represent some foundational colours does not imply that they should be excluded from the domain of all our representations, which undermines the most natural motivation for this objection. A conciliatory thinker should therefore try to develop another response.

The second response is related. I claim that your experience tells you something about the relationships between ash, charcoal, and other colours. It is tempting to respond that your experience merely tells you something about the relationships between the phenomenal characters of ash experiences, charcoal experiences, and other colour experiences. In that case, perhaps your experience merely tells you that the phenomenal characters of these experiences together fill a path through phenomenal space. I think that this response is introspectively implausible; it seems clear to me that your experience tells you something about the relationships between ash, charcoal, etc. Analogously, if you experience two objects as close together then your experience seems to be telling you something about those objects, and does not seem to be merely telling you something about your own phenomenology. Additionally, and perhaps most importantly, it is dialectically unsatisfying for a conciliatory thinker to insist that your experience only tells you something about your own experience's phenomenal characters. Just take anything that appears to be part of the structure of your colour experiences. If in response to any incompatibility a conciliatory thinker can just respond that it is really a part of the structure of your experiences' phenomenal characters then that would trivialize STRUCTURE. Yet STRUCTURE is supposed to be a substantive and interesting claim.

The third response targets the reasoning that led us to MISSING. For concreteness, let us again focus on grey $_{300}$. Grey $_{300}$ objects do not reliably produce ash experiences. Grey $_{300}$ objects also do not reliably produce charcoal experiences. But grey $_{300}$ objects reliably produce either an ash experience or a charcoal experience. That is, grey $_{300}$ objects reliably produce ash-or-charcoal experiences. One might then think that RELIABLE PRODUCTION implies that ash-or-charcoal experiences represent a disjunction that includes grey $_{300}$, which, when generalized, would establish that MISSING is false. The problem with this response is that it seems that the only way to have an ash-or-charcoal experience is to have an ash experience or to have a charcoal experience. If that is right then ash-or-charcoal experiences do not represent a disjunction that includes grey $_{300}$. 
Of course, a conciliatory thinker might insist that, despite what I just said, one can have an ash-or-charcoal experience without having either an ash experience or a charcoal experience. The trouble is that it is hard to make sense of this possibility, at least if we are thinking about colour experiences in the usual way. Perhaps there is another, better way of thinking about colour experiences. But I am sceptical. I suspect that any alternative will be unacceptably counter-intuitve.

The fourth response targets one of my background assumptions. According to this response, even though foundational colours are as fine-grained as spectral dispositions, grey $_{300}$ is not a colour. In that case, my arguments do not establish that there is an intermediate colour that is unrepresentable, and therefore my arguments do not establish MISSING.

The best way to bring out the problem with this response is to consider a wall that is uniformly grey ${ }_{300}$. Is that wall coloured? Intuitively, it is. Consider an object that gradually transitions from grey $_{256}$ to grey $_{343}$. Intuitively, it is always coloured. At no moment is it colourless. Therefore, intuitively, it is still coloured even when it has a spectral disposition that will not reliably produce any particular colour experience. In support of this intuition, keep in mind that even at those moments it still reliably produces some colour experience or other, and therefore always looks coloured. For example, a wall with that spectral disposition would always look charcoal or ash, and it is extremely counter-intuitive to say that the wall is none the less colourless. Perhaps some will be willing to bite this bullet. But I suspect that most will not.

A conciliatory thinker might modify her response to accommodate the intuition that the wall is coloured. In particular, she might claim that the wall is coloured without being any specific shade. The trouble is that it is hard to make metaphysical sense of this claim. It seems just as paradoxical as the claim that there are polygons that are not three-sided, four-sided, five-sided, and so on.

As a way of making metaphysical sense of the claim that a wall can be coloured without being any specific shade, a conciliatory thinker might invoke metaphysical indeterminacy. In particular, she might claim that it is metaphysically determinate that the wall is coloured even though it is metaphysically indeterminate which colour it instantiates. The trouble is that it is not any easier to make sense of this claim. It is important to keep in mind that what is at issue here is whether there is some indeterminacy in what properties are instantiated. What is not at issue is whether there is some indeterminacy in 
what we represent, which is why standard theories of indeterminacy, such as those advanced by supervaluationists, will not help.

Further, even if there is a way to make sense of this kind of metaphysical indeterminacy, I doubt that many conciliatory thinkers will want their theory of colour to depend on it. For example, one possibility is that, just as some think that parthood comes in degrees so that some rocks are part of Mount Kilimanjaro to degrees less than one, perhaps instantiation also comes in degrees so that a grey ${ }_{300}$ wall instantiates both ash and charcoal to degrees less than one. Another possibility is that colours are vague properties in that it is indeterminate which colours are identical to a grey ${ }_{300}$ wall's colour. Regardless, I doubt that many conciliatory thinkers will want their theory to depend on such controversial - and perhaps even unintelligibleviews about the nature of properties.

The fifth response targets another of my background assumptions. I assumed that the foundational colours are as fine-grained as spectral dispositions. According to this response grey $_{300}$ is too fine-grained to be a colour. If that is right, my arguments do not establish that there is an intermediate colour that is unrepresentable, and therefore my arguments do not establish MISSING.

Most conciliatory thinkers cannot endorse this response. Here is why. Most conciliatory thinkers believe that colours are speciesindependent in that, for example, hummingbirds and humans both see shades of grey even though hummingbirds can see more fine-grained shades of grey. This belief has an important consequence. Consider any two objects with different spectral dispositions. Regardless of which objects we are considering, there is some possible creature that could reliably detect the difference between them. ${ }^{31}$ Given what we said about hummingbirds and humans, we should think of this creature as discriminating the colours of the objects. Therefore, the foundational colours must be as fine-grained as spectral dispositions.

Some conciliatory thinkers claim that colours are species-relative. For example, they claim that hummingbirds see charcoal-forhummingbirds and humans see charcoal-for-humans and these colours are not merely different different disjunctions of the same

${ }^{31}$ This is a near-trivial consequence of signal detection theory. Just consider that if they reflect light differently then, where $\mathrm{d}^{\prime}$ is the distance between the peak of the two probability distributions at some wavelength, $\mathrm{d}^{\prime} \neq 0$. And if $\mathrm{d}^{\prime} \neq 0$ for two signals then there is always some detector that can reliably discriminate them. For more about signal detection theory, see Gescheider 1997. 
foundational colours. ${ }^{32}$ If we develop this proposal in the most natural way then what makes an object charcoal-for-humans is that it reliably produces charcoal experiences in humans. Likewise for ash-forhumans, peach-for-humans, rust-for-humans, and so on. In that case, objects that do not reliably cause any particular experience are not ash-for-humans, charcoal-for-humans, peach-for-humans, rustfor-humans, and so on. That leaves the conciliatory thinker in the same place as before: either she must deny that these objects are coloured (which is counter-intuitive) or she must claim that they are coloured without being any particular shade (which might not be metaphysically intelligible). Alternately, she might give some other account of what makes an object ash-for-human, though it is not clear what such an account would look like.

The sixth response is that even though grey $_{300}$ is a foundational colour, it is not between charcoal and ash in the colour solid. If that is right, my arguments do not establish MIssing. But where else might grey $_{300}$ be? For example, suppose it is instead between two shades of yellow and is therefore itself a shade of yellow. In that case, a wall that is slowly transitioning from charcoal to ash will at some point be a shade of yellow-it will be a shade of yellow for the short time that it is grey $_{300}$. That is highly counter-intuitive.

The seventh response is that I have misunderstood STRUCTURE because, on a correct understanding, the fullness of some transitions in colour is not part of the structure of our colour experiences. However, when we think about the structure of our colour experiences we are naturally led to think that it is captured, at least in part, by traditional colour solids. Moreover, it seems to be constitutive of a traditional colour solid that not only do distances along a path correspond to degrees of similarity, but that all the paths through them are full, so that there are no missing shades. Equivalently, when we think about the structure of our spatial experiences, we are naturally led to think of it as something captured, at least in part, by empty volumes, and it seems to be constitutive of these volumes that paths through them are full, so that there are no missing points. It might help to imagine a colour solid in which each colour is set apart from the others, like stars in the night sky. Intuitively, that colour solid leaves something out; for lack of a better term, we might say that it fails to capture the unity of the colours.

32 See Cohen 2004, Jackson and Pargetter 1987, Kalderon 2007, and McLaughlin 2003. For simplicity, I am overlooking the fact that most colour relativists think that the colours are relative to particular observers and particular contexts rather than just species. 
Thus, even if there is some other way of understanding STRUCTURE, I doubt that it will help the conciliatory thinker circumvent the problem.

I think it is helpful to distinguish this response from another, stronger response. If one abandoned STRUCTURE then one could brush aside both the similarity objection and my objection. In support of this stronger response one might insist that the connection between colours and colour experiences should not be any tighter than the connection between shapes and shape experiences. This stronger response would certainly make it easier to hold onto DEPENDENCE because there would not be as many conditions for a property to count as a colour. However, the resulting view of colour would be correspondingly less interesting and perhaps even trivial given that our colour experiences have physical causes. Still, this is the cleanest response to the problem.

The eighth response is really just a modification of RELIABLE PRODUCTION. The failure of RELIABLE PRODUCTION is ultimately due to the existence of foundational colours that do not reliably cause any particular experience. A natural way to avoid this problem is to lower the threshold below fifty percent. ${ }^{33}$ The problem with this modification is that the colours will no longer preserve the similarity orderings that are part of the structure of our colour experiences. Let us again use a more abstract perspective to clarify the relevant issues. Consider the same series of foundational colours as before, grey $_{256} \ldots$ grey $_{343}$, and the same three experiences as before, E1, E2, and $\mathrm{E}_{3}$, but let us now lower the threshold:

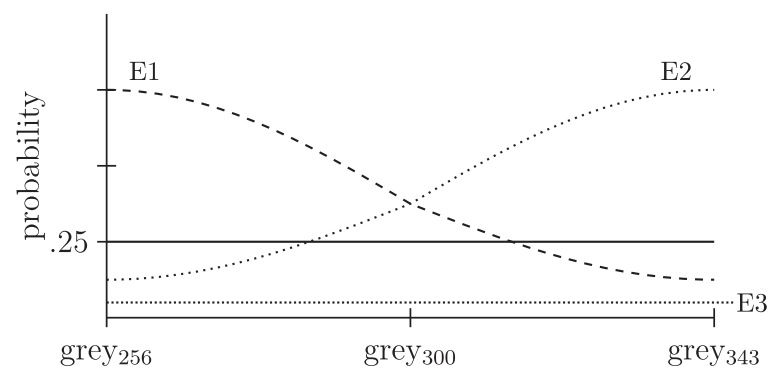

foundational colours

${ }^{33}$ I am assuming for concreteness that for each colour experience there is some foundational colour that reliably produces it. However, nothing hinges on this assumption. Just note that the problems with reliable production and this modification form a dilemma for any non-gerrymandered choice of thresholds: the threshold will either be so high that some foundational colours will fail to cross it for any experience, or the threshold will be so low that some foundational colours will cross it for two experiences. 
A consequence of lowering the threshold is that these experiences represent overlapping disjunctions of foundational colours. Let us again use 'charcoal' so that it picks out the colour represented by E1 and 'ash' so that it picks out the colour represented by E2. In that case we can depict the relationship between these colours:

$$
\begin{aligned}
& \overbrace{\ldots \vee \text { grey }_{256} \vee \ldots \vee \text { grey }_{300} \vee \ldots}^{\text {charcoal }} \\
& \underbrace{\ldots \vee \text { grey }_{300} \vee \ldots \vee \operatorname{grey}_{343} \vee \ldots}_{\text {ash }}
\end{aligned}
$$

Here is the problem. Suppose you are having an ash experience of two paint chips and a charcoal experience of a third paint chip. Your experience will thereby tell you that the colour of the first paint chip is more similar to the colour of the second paint chip than to the third paint chip. As a result, it is part of the structure of your experience: if two things are ash then they have colours that resemble each other more than charcoal. The problem is that this conditional is false if we lower the threshold. Just note that if something is grey $_{300}$ then it is both charcoal and ash, in which case there is something that is ash that resembles charcoal things just as much as other ash things. Therefore, lowering the threshold is inconsistent with STRUCTURE.

It is worth taking a moment to reflect on why this is a surprising result. As noted in the introduction, some people think that colours cannot be identical with disjunctions of spectral dispositions because the relevant disjunctions will be too heterogenous to preserve the similarity orderings among the colours. These people think that this is a decisive problem for colour physicalism and they use it to motivate other variants of conciliatory thinking. However, we have just established the surprising result that if a conciliatory thinker lowers the threshold below fifty percent then she cannot preserve the similarity orderings among the colours even if the colours just minimally depend on spectral dispositions.

The ninth response is to invoke representational indeterminacy. Because there are so many theories of representational indeterminacy, and because it is hard to see how invoking representational indeterminacy could help the conciliatory thinker, this is a difficult response to evaluate. As a preliminary, I think it helps to note that many of the standard theories of representational indeterminacy were developed to undermine sorites paradoxes and, despite the existence of superficial similarities, like talk about where to place a cut-off in a series, 
the problem for conciliatory thinking is not an instance of a sorites paradox. To appreciate why, consider that there is no analogue to DEPENDENCE or STRUCTURE in sorites paradoxes. Consider also that the problem for conciliatory thinking does not depend on a so-called 'sorites premiss', which would have a form like: if a grey ${ }_{n}$ object is charcoal then a grey ${ }_{n+1}$ object is charcoal.

In any case, there are reasons to doubt that an appeal to representational indeterminacy will help the conciliatory thinker. Returning to our example, suppose that it is indeterminate which of the following properties a given experience represents:

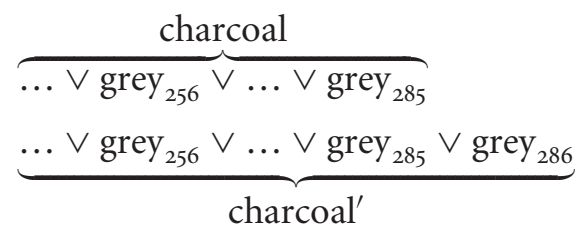

The problem is that, at least for most colour experiences, it does not just seem that there is some colour that we are representing. It also seems that we know which colour it is, at least under one of its modes of presentation. Yet if it is indeterminate whether our experience is representing charcoal or charcoal' then we presumably cannot know which colour we are representing. At best, we can only know that there is some colour that we are representing. That is highly counter-intuitive.

A second problem is that representational indeterminacy in the extension of 'certain observer', 'certain context', and 'reliable' might not be enough to avoid the problem. Returning again to our example, despite indeterminacy in who is the relevant observer, etc., it might still be the case that grey $_{300}$ objects do not produce any experience in more than fifty percent of cases. Therefore, given RELIABLE PRODUCTION, it might still be the case that none of our experiences represent a disjunction that includes grey $_{300}$. As a result, even if there is some indeterminacy in which properties our experiences represent, that does not automatically solve the problem unless one gives up RELIABLE PRODUCTION. And, as we have seen, it is unclear what could replace RELIABLE PRODUCTION.

A third problem is that if it is indeterminate whether any of our experiences represent a disjunction of colours that includes grey $_{300}$ then it is indeterminate whether ash, charcoal, etc. fill a path through colour space. In that case it is indeterminate whether STRUCTURE is true. That does not seem like an improvement. 
Perhaps a conciliatory thinker can develop a clever, new theory of representational indeterminacy that sidesteps these problems. But I am sceptical. In addition, it should at least embarrass the conciliatory thinker that her ability to integrate her commitments depends on a controversial, new theory of representational indeterminacy.

I just considered nine responses. There are doubtless other ways to defend or modify RELIABLE PRODUCTION, and there might even be a way to develop one of these responses into something less problematic. Regardless, it should be clear that RELIABLE PRODUCTION and its most straightforward modification have a serious problem. Let us therefore investigate another strategy.

\section{Alternative strategy}

RELIABLE PRODUCTION uses the probabilities linking colour experiences and foundational colours to pick out the relevant colour disjunctions. An alternative strategy is to instead include the probabilities in what is represented. Let us develop this alternative strategy with an example. Consider an arbitrary colour experience as well as foundational colours grey $_{256}$, grey $_{257}$, etc. Suppose the probability that an instance of this experience was produced by grey ${ }_{256}$ is 0.02 , the probability that an instance of this experience was produced by grey $_{257}$ is 0.05 , and there are similar probabilities for each of the other foundational colours. The causal information provided by this experience is: the probability that the relevant object has foundational colour $\operatorname{grey}_{256}$ is 0.02 , the probability that the relevant object has foundational colour grey $_{257}$ is 0.05 , and so on. According to the alternative strategy, this experience represents a property like having a probability of 0.02 of being colour grey ${ }_{256}$, having a probability of 0.05 of being colour grey $_{257}$, and so on. The motivation for this strategy is the thought that what a colour experience tells us corresponds to the causal information it provides.

One difference between this strategy and the last strategy is that it focuses on different probabilities. The reliable production strategy focused on the probability that exposure to a foundational colour will produce a certain experience (a likelihood approach). This strategy switches focus to the probability that an experience was produced by a certain foundational colour (a posterior probability approach). 
There are two ways to think about the property having a probability of 0.02 of being colour grey ${ }_{256}$, having a probability of 0.05 of being colour grey $_{257}$, and so on. According to the first way, we should think of it as itself a colour. Perhaps it is a special kind of weighted disjunction. However, that would have absurd consequences. On the one hand, if we think of the probabilities as corresponding to subjective probabilities then it has the incredible consequence that if I change my credences about the foundational colour of an object then the object thereby changes its colour. On the other hand, if we think of the probabilities as corresponding to objective probabilities then, except in abnormal situations, nothing instantiates these properties. For instance, if an object is grey $_{256}$ then, if anything, it has the rival property having a probability of 1.00 of being grey $_{256}$. But one of the primary motivations for conciliatory thinking is the conviction that we represent colours that are actually instantiated.

The second way of thinking about this property is that it is not itself a colour. In that case, the experience does not represent a nonfoundational colour that includes grey $_{256}$ and grey $_{257}$ as disjuncts. Instead, it merely tells us something about the probability that the object has various colours. However, that is implausible because at least some colour experiences do not tell us anything probabilistic. Just look around. If your experiences are like mine then they will tell you which surfaces have which colours, and there is nothing probabilistic about that. For instance, you might be tempted to say of an object's colour, 'That's my favourite colour'. But you will rarely be tempted to say things like, 'Look at one of the possible colours of this object' or 'That object has some probability of having my favourite colour'. In addition, this property would not preserve the structure of our experiences. For example, suppose you are having a uniform experience of a wall. Your experience might thereby tell you that the entire wall is the same colour. But, if your experience merely represents the probability that each part of the wall is grey $_{256}$, grey $_{257}$, etc., and does not represent any less foundational colour, then it would not thereby tell you that the entire wall is the same colour. Instead, it would tell you the probability that the wall is the same colour is less than 1 because there will always be some probability that the left-half is grey ${ }_{256}$ and the right-half is grey $_{257}$. As a result, the colours you represent would not preserve the structure of your colour experiences.

I conclude that this strategy has significant problems. 


\section{Conclusion}

The definitive claims of conciliatory thinking are the claim about structure (that the colours preserve the structure of our experiences) and the claim about dependence (that the colours depend on physical properties). The most straightforward strategy for integrating these claims centres around RELIABLE PRODUCTION but I argued that this strategy is incompatible with the claims it was supposed to integrate. How should conciliatory thinkers respond? If they want to remain conciliatory thinkers they must either find another strategy or reject one of the assumptions that help generate the incompatibility. However, there is no obvious replacement and rejecting any of the assumptions would at best have surprising, far-reaching, and counter-intuitive consequences. That leaves conciliatory thinkers in a difficult spot. ${ }^{34}$

\section{References}

Armstrong, David 1968: A Materialist Theory of the Mind. London: Routledge and K. Paul.

- 1987: 'Smart and Secondary Qualities'. In Pettit, Sylvan, and Norman 1987, pp. 1-15.

Averill, Edward 1985: 'Color and the Anthropocentric Problem'. Journal of Philosophy, 82, pp. 281-304.

Bayne, Tim, Axel Cleeremans, and Patrick Wilken (eds) 2009: The Oxford Companion to Consciousness. New York, NY: Oxford University Press.

Blakemore, Colin (ed.) 1990: Vision: Coding and Efficiency. New York, NY: Cambridge University Press.

Boghossian, Paul and David Velleman 1989: 'Colour as a Secondary Quality'. Mind, 98, pp. 67-106.

1991: 'Physicalist Theories of Color'. The Philosophical Review, 100, pp. 81-103.

\footnotetext{
${ }^{34}$ It took a village to raise this paper. It started out as a confused and unsuccessful attempt to undermine colour physicalism by pointing out that colour representation is vague. Thanks to others, it matured. Jim Pryor and Stephen Schiffer were patient, attentive, and demanding supervisors. Shamik Dasgupta, Matt Kotzen, Geoff Lee, and Jon Simon commented on multiple drafts over four years. Other helpful villagers included: Yuval Avnur, David B. Barnett, Ned Block, Alex Byrne, Jonathan Cohen, Jonathan Cottrell, Will Davies, Cian Dorr, Dana Evan, Matt Evans, Kit Fine, Chris Frey, Don Garrett, Benj Hellie, David Hilbert, Jed Lewinsohn, Colin Marshall, Brian McLaughlin, Adam Pautz, Ian Phillips, Nicholas Riggle, Karl Schafer, Kevin Scharp, Nico Silins, Brad Skow, Sharon Street, Michael Strevens, audiences at both NYU and St. Andrews, two anonymous referees, and the editor of this journal.
} 
Bradley, Peter and Michael Tye 2001: 'Of Colors, Kestrels,

Caterpillars, and Leaves'. Journal of Philosophy, 98, pp. 469-87.

Broackes, Justin 1992: 'The Autonomy of Colour'. In Charles and

Lennon 1992, pp. 421-65.

Broad, Charlie Dunbar 1914: Perception, Physics and Reality: An

Enquiry into the Information that Physical Science can Supply

about the Real. New York, NY: Cambridge University Press.

Byrne, Alex 2003: 'Color and Similarity'. Philosophy and

Phenomenological Research, 66, pp. 641-65.

Byrne, Alex and David Hilbert 1997a: 'Colors and Reflectances'.

In Byrne and Hilbert 1997c, pp. 263-88.

- 1997b: 'Introduction'. In Byrne and Hilbert 1997c, pp. xi-xxviii.

-1997c: Readings on Color: The Philosophy of Color. New York,

NY: Oxford University Press.

2003: 'Color Realism and Color Science'. Behavioral and Brain Sciences, 26, pp. 3-21.

Campbell, John 1993: 'A Simple View of Colour'. In Haldane and Wright 1993, pp. 257-69.

2002: Reference and Consciousness. New York, NY: Oxford University Press.

Charles, David and Kathleen Lennon (eds) 1992: Reduction, Explanation, and Realism. New York, NY: Oxford University Press. Chung-Ying, Cheng 1975: Philosophical Aspects of the Mind-Body Problem. Honolulu, HI: University Press of Hawaii.

Cohen, Jonathan 2003a: 'Color: A Functionalist Proposal'. Philosophical Studies, 113, pp. 1-42.

2003b: 'On The Structural Properties of the Colors'. Australasian Journal of Philosophy, 81, pp. 78-95.

2004: 'Color Properties and Color Ascriptions: A Relationalist Manifesto'. The Philosophical Review, 113, pp. 451-506.

Cornman, James 1975: Perception, Common Sense, and Science. New Haven, CT: Yale University Press.

Dicke, Robert 1953: 'The Effect of Collisions upon the Doppler Width of Spectral Lines'. Physical Review, 89, pp. 472-73.

Dretske, Fred 1981: Knowledge and the Flow of Information. Cambridge, MA: MIT Press.

1994: Naturalizing the Mind. Cambridge, MA: MIT Press.

Evans, Gareth 1984: 'Things Without the Mind'. In van Straaten 1984, pp. 76-116.

Fara, Delia Graff 2001: 'Phenomenal Continua and the Sorites'. Mind, 110, pp. 905-35, Published under the name 'Delia Graff'. 
Fox, Mark 2006: Quantum Optics: An Introduction. New York, NY: Oxford University Press.

Gescheider, George 1997: Psychophysics: The Fundamentals. Mahwah, NJ: Lawrence Erlbaum Associates.

Haldane, John and Crispen Wright (eds) 1993: Reality, Representation, and Projection. New York, NY: Oxford University Press.

Hardin, C. L. 1988a: Color for Philosophers: Unweaving the Rainbow. Indianapolis, IN: Hackett.

1988b: 'Phenomenal Colors and Sorites'. Nô̂s, 22, pp. 213-34.

2003: 'A Spectral Reflectance Doth not a Color Make'. Journal of Philosophy, 100, pp. 191-202.

Harding, Gregory 1991: 'Color and the Mind-Body Problem'. Review of Metaphysics, 45, pp. 289-307.

Harman, Gilbert 1996: 'Explaining Objective Color in Terms of Subjective Responses'. In Villanueva 1996, pp. 1-17.

Hellie, Benj 2005: 'Noise and Perceptual Indiscriminability'. Mind, 114, pp. 481-508.

Hilbert, David 1987: Color and Color Perception: A Study in Anthropocentric Realism. Stanford, California: CSLI.

Honderich, Ted (ed.) 1985: Morality and Objectivity. London: Routledge \& Kegan Paul.

Hulbert, Anya 1986: 'Formal Connections Between Lightness Algorithms'. Journal of the Optical Society of America A, 3, pp. 1684-93.

Hurvich, Leo 1981: Color Vision: An Introduction. Sunderland, MA: Sinauer Associates.

Jackson, Frank 1996: 'The Primary Quality View of Color'. Philosophical Perspectives, 10, pp. 199-219.

Jackson, Frank and Robert Pargetter 1987: 'An Objectivist's Guide to Subjectivism about Color'. Revue Internationale de Philosophie, 41, pp. 127-41.

Johnston, Mark 1992: 'How to Speak of the Colors'. Philosophical Studies, 68, pp. 221-63.

Kalderon, Mark 2007: 'Color Pluralism'. The Philosophical Review, 116 , pp. 563-601.

Kripke, Saul 1980: Naming and Necessity. Cambridge, MA: Harvard University Press.

Land, Edwin 1977: 'The Retinex Theory of Color Vision'. Scientific American, 237, pp. 108-28.

Lewis, David 1997: 'Naming the Colours'. Australasian Journal of Philosophy, 75, pp. 325-42. 
Lycan, William 1996: Consciousness and Experience. Cambridge, MA: MIT Press.

Matthen, Mohan 1999: 'The Disunity of Color'. The Philosophical Review, 108, pp. 47-84.

Maund, Berry 1995: Colours: Their Nature and Representation. New York, NY: Cambridge University Press.

2006: 'Color'. Stanford Encyclopedia of Philosophy [online encyclopedia], Fall 2006 Edition, ed. Edward N. Zalta, <http://plato. stanford.edu/entries/color/>.

Mausfeld, Rainer and Dieter Heyer (eds) 2003: Colour: Connecting the Mind to the Physical World. New York, NY: Oxford University Press.

Maxwell, James 1881: A Treatise on Electricity and Magnetism. London: Clarendon Press.

McDowell, John 1985: 'Values and Secondary Qualities'. In Honderich 1985, pp. 110-29.

McGinn, Colin 1983: The Subjective View. New York, NY: Oxford University Press.

McLaughlin, Brian 2003: 'The Place of Color in Nature'. In Mausfeld and Heyer 2003, pp. 475-505.

McLaughlin, Brian and Zolton Jakab 2003: 'Why Not Color Physicalism Without Color Absolutism?' Behavioral and Brain Sciences, 26, pp. 34-5.

Morrison, John and David Anderson 2011: 'Visual Noise Due to Quantum Indeterminacies'. Columbia University Academic Commons [digital repository], <http://academiccommons. columbia.edu/item/ac:135042>.

Newton, Isaac 1672: 'A Letter of Mr. Isaac Newton ... containing his

New Theory about Light and Colors'. Philosophical Transactions of the Royal Society, 7, pp. 3075-87.

Pautz, Adam 2003: 'Have Byrne and Hilbert Answered Hardin's Challenge?' Behavioral and Brain Sciences, 26, pp. 44-5.

2006: 'Can the Colour Physicalist Explain Colour Structure in Terms of Colour Experience?' Australasian Journal of Philosophy, 84, pp. 535-64.

2009: 'Philosophical Issues Concerning Colour'. In Bayne et al. 2009, pp. 144-9.

Peacocke, Christopher 1984: 'Colour Concepts and Colour Experience'. Synthese, 58, pp. 365-82.

Pelli, Denis 1990: 'The Quantum Efficiency of Vision'. In Blakemore 1990, pp. 3-24. 
Pettit, Philip, Richard Sylvan, and Jean Norman (eds) 1987: Metaphysics and Morality: Essays in Honour of J. J. C. Smart. New York, NY: Blackwell Publishers.

Smart, John 1975: 'On Some Criticisms of a Physicalist Theory of Colors'. In Chung-Ying 1975, pp. 54-63.

Strawson, Galen 1989: 'Red and "Red"'. Synthese, 78, pp. 193-232.

Thompson, Evan 1995: Colour Vision: A Study in Cognitive Science and the Philosophy of Perception. London: Routledge Press.

Tye, Michael 1995: Ten Problems of Consciousness: A Representational Theory of the Phenomenal Mind. Cambridge, MA: MIT Press.

2002: Consciousness, Color, and Content. Cambridge, MA: MIT Press.

van Straaten, Zak (ed.) 1984: Philosophical Subjects: Essays Presented to P. F. Strawson. New York, NY: Oxford University Peess.

Villanueva, Enrique (ed.) 1996: Philosophical Issues, Vol. 7. Atascadero, CA: Ridgeview Publishing.

Wittgenstein, Ludwig 1921: Tractatus Logico-philosophicus. London: Routledge \& Kegan Paul.

Yablo, Stephen 1995: 'Singling out Properties'. Philosophical Perspectives, 9, pp. 477-502. 